\title{
Selective Production of Maleic Acid from Furfural via a Cascade Approach Combining Photochemistry and Electro- or Biochemistry
}

\author{
Shanmugam Thiyagarajan,* David Franciolus, Roel J. M. Bisselink, Tom A. Ewing, Carmen G. Boeriu,
} and Jacco van Haveren

Cite This: ACS Sustainable Chem. Eng. 2020, 8, 10626-10632

Read Online

\section{ACCESS I}

Џlll Metrics \& More

Article Recommendations

Supporting Information

ABSTRACT: Starting from furfural, maleic acid is efficiently synthesized in two steps under very mild conditions. In the first step, 5 -hydroxy-2 $(5 H)$-furanone is synthesized via photochemical oxidation and proposed as a stable intermediate. Subsequent oxidation in the second step, by either an electrochemical or enzymatic process, results in maleic acid in high yield and selectivity.

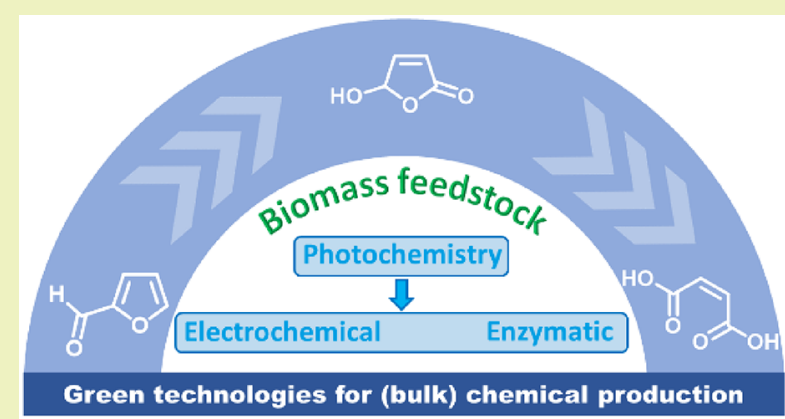

KEYWORDS: Maleic acid, Enzymatic oxidation, Electrochemical oxidation, TEMPO, Nitroxyl radicals

\section{INTRODUCTION}

In the past few decades, there has been a growing interest in reducing the dependency on fossil-based feedstocks and replacing them with renewable biomass as a sustainable source for the production of chemicals and materials. ${ }^{1-4}$ In parallel to this quest, the investigation of greener technologies (such as photochemical, electrochemical, and biocatalytic processes) for the efficient conversion of such biomass into chemicals is also attractive. Most of these processes, in addition to high atom efficiency, will substantially reduce pollution and energy consumption, thereby lowering the production costs and resulting in less or no waste side-streams. ${ }^{5,6}$

Maleic acid (MA) is an important raw material that finds multiple applications in the chemical industry, such as in manufacturing of unsaturated polyester resins, lubricant additives, surface coatings, textiles, photographic chemicals, plasticizers, pharmaceutical products, and agricultural chemicals. $^{7-13}$ In our ongoing research, MA is widely being used to synthesize chemicals for different applications, in particular biobased aromatic (bulk) chemicals. ${ }^{14,15}$ Biobased aromatic compounds can be conveniently synthesized via a Diels-Alder (DA) cycloaddition of furanics (as diene) with maleic acid anhydride (dienophile). Subsequent dehydration (also known as aromatization) of the DA adduct leads to aromatic compounds. ${ }^{14,15}$ This strategy is regarded as an interesting technology for the production of biobased aromatic chemicals, since both diene and dienophile can be derived from cellulosic biomass. The most promising dienes, such as furan, (di)methylfuran, and furfural, are synthesized from C5/C6 sugars in high yields according to procedures that are in agreement with industrial demands for large-scale production. ${ }^{16-18}$ Furfural is already commercially produced at a scale of around 280-400 kton/year from carbohydrates. ${ }^{19-22}$ However, the development of cost-efficient routes for the production of MA starting from biomass is still challenging. To produce aromatic chemicals and other materials based upon biobased MA, it is essential to develop processes using green methodologies that can meet the industrial demands for the production of MA from renewable resources.

Currently, MA is commercially produced by hydrolysis of maleic acid anhydride, which in turn is obtained from the vapor-phase oxidation of benzene or $n$-butane. ${ }^{23,24}$ Starting from $100 \mathrm{~mol}$ of benzene, $73 \mathrm{~mol}$ is oxidized to maleic anhydride and $23 \mathrm{~mol}$ is "burned off" under the applied conditions, leaving $4 \mathrm{~mol}$ of unreacted benzene in the commercial process. $^{23}$

Lately, alternative resources have been investigated to circumvent the use of fossil derived feedstocks. In particular, biomass-derived platform chemicals like butanol, levulinic acid, 5-hydroxymethylfurfural (HMF), and furfural were investigated as starting materials for the synthesis of MA. ${ }^{6-11}$ Among these platform chemicals, furfural is an interesting

Received: April 19, 2020

Revised: June 24, 2020

Published: July 7, 2020 
Scheme 1. Two-Step Strategy for Synthesizing Maleic Acid (3) from Furfural (1): Step 1, Photochemical Oxidation, and Step 2, (a) Electrochemical or (b) Enzymatic Oxidation

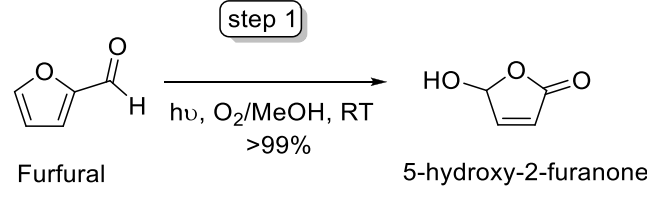

(1)

(2)

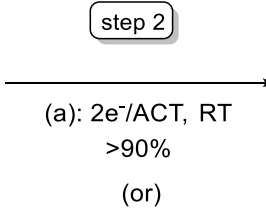

(b): Laccase/TEMPO, Air,RT $>99 \%$

Scheme 2. Chemical Equilibrium between 5-Hydroxy-2(5H)-furanone (2), cis- $\beta$-Formylacrylic Acid (FAA, 2a), and the Conjugated Base $2 b$

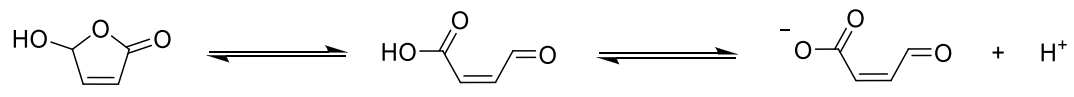

(2)

(2a)

$(2 b)$

substrate since its commercial production is already established starting from carbohydrates. 22,25

The first report of the production of MA from furfural dates back to 1 century ago, when Yabuta patented the electrochemical oxidation of furfural to MA in sulfuric acid at lead (oxide) anodes. ${ }^{26}$ This was followed by the work of Sessions, who in 1928 demonstrated the vapor-phase oxidation of furfural to MA at high temperature $\left(300-350{ }^{\circ} \mathrm{C}\right) ;^{27}$ however, the yields were not mentioned in that report. Since then, a wide range of investigations have been carried out to improve the process, including gas-phase reactions, ${ }^{28,29}$ oxidation using a high pressure of $\mathrm{O}_{2}{ }^{30-32}$ or chemical oxidants, ${ }^{33-35}$ and electrochemical oxidation. ${ }^{26,36-42}$ In parallel to our investigations, we came across two recent reports: one by $\mathrm{Wu}$ et al., describing the use of metal chalcogenides as electrocatalyst and water as the oxygen source to produce 5-hydroxy- $2(5 \mathrm{H})$ furanone from furfural at $83.6 \%$ selectivity and in parallel to MA at $8.8 \%$ selectivity, ${ }^{43}$ and the other by Román et al., who oxidized furfural at platinum deposited on plain carbon cloth, thereby obtaining mainly 2-furoic acid, 5-hydroxy-2(5H)furanone, and hydroxyfuroic acid, with MA being a minor product. $^{44}$

Nevertheless, all these conditions require either high temperature, high oxygen pressure, a large excess of chemical oxidants like $\mathrm{H}_{2} \mathrm{O}_{2}$, or a large excess of charge to achieve maleic acid/anhydride in reasonable to good yields. These extreme conditions are unfortunately not favorable for producing such chemicals in large quantities at low to reasonable prices.

Herein, we describe a simple two-step procedure to synthesize MA efficiently starting from furfural. Step 1 is a photochemical oxidation of furfural to 5-hydroxy- $2(5 H)$ furanone, and step 2 is a nitroxyl radical-mediated oxidation to MA via either an electrochemical or enzymatic oxidation process. It is important to mention here that the reaction conditions employed in both steps are very mild, resulting in higher selectivity to the desired product. This new strategy will promote not only the greener production of MA but also greener technologies for (bulk) chemicals production.

\section{RESULTS AND DISCUSSION}

Most of the reports dealing with direct oxidation of furfural (1) to maleic acid (3) describe as a common fact that furfural is first oxidized to several unstable intermediates and then finally to MA. ${ }^{30,45}$ Interestingly, a few of those reports discussed the formation of stable intermediates such as 2 -furanone, ${ }^{30,36} 2$ furanol, ${ }^{32}$ and 5-hydroxy-2(5H)-furanone. ${ }^{26,37-40}$ These results prompted us to first synthesize one of these stable intermediates, i.e., 5-hydroxy-2(5H)-furanone (2), starting from furfural, and then subsequently oxidize the intermediate to MA in the second step (Scheme 1).

Since furfural is a highly reactive molecule, it is envisioned that converting it into a stable intermediate will circumvent undesirable byproduct formation under oxidation reaction conditions. Recently, a similar approach was employed to synthesize $\gamma$-butyrolactone starting from furfural via 5-hydroxy$2(5 H)$-furanone as an intermediate. ${ }^{46}$

Step 1: Synthesis of 2 via Photochemical Oxidation. The synthesis of $\mathbf{2}$ is well-documented in the literature: $\mathbf{1}$ is photochemically oxidized at room temperature by singlet oxygen generated using a catalytic amount of methylene blue as photosensitizer. The resulting endoperoxide is unstable and simultaneously decarbonylated to give 2 . Besides methylene blue, Rose Bengal was also used as photosensitizer, and typically quantitative yields of the desired product were reported. $^{47,48}$ The use of sunlight in solar photoreactors has also been successfully demonstrated for the synthesis of $2,{ }^{49}$ which is already a convincing argument that the production of 2 at commercial scale can be performed economically in a green, sustainable manner. Besides furfural, 2 can also be synthesized starting from furan, 2-furoic acid, or furfuryl alcohol using similar conditions. While starting from 2-furoic acid or furfuryl alcohol results in similar yields, ${ }^{50-52}$ a lower yield (35\%) was reported when starting from furan. ${ }^{53}$ Using a custom-made photoreactor setup (see Supporting Information), the photochemical oxidation of $\mathbf{1}$ was reproduced in good yield and high selectivity $(>95 \%)$ to 2 . The crude product was further purified by Reveleris flash chromatography to obtain 2 in $>99 \%$ purity. Spectroscopic investigations by ${ }^{1} \mathrm{H}$ and ${ }^{13} \mathrm{C}$ NMR and GC-MS confirmed the structure of the desired compound.

Step 2: (a) Electrochemical Oxidation of 2 to Maleic Acid 3. Under aqueous conditions, $\mathbf{2}$ is in equilibrium with various compounds, including its tautomer $\beta$-formylacrylic acid (FAA, 2a) (Scheme 2). 2 accounts for $30-60 \%$ of the speciation under acidic conditions $(0<\mathrm{pH}<4)$, with the conjugated base of FAA, $\mathbf{2 b}$, being the dominant species at $\mathrm{pH}$ $>6 .^{46}$ The electrochemical oxidation of 1 to 3 using $\mathrm{PbO}_{2}$ in 


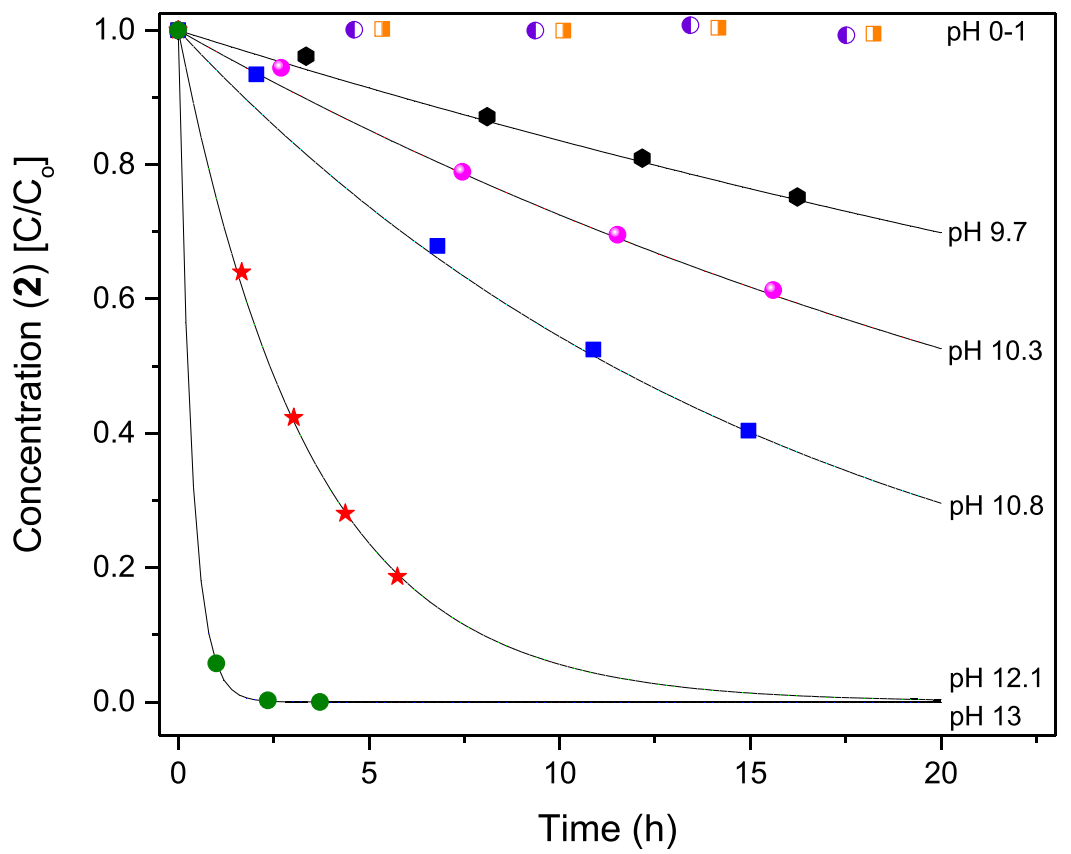

Figure 1. Degradation of 2 at room temperature under various $\mathrm{pH}$ conditions.
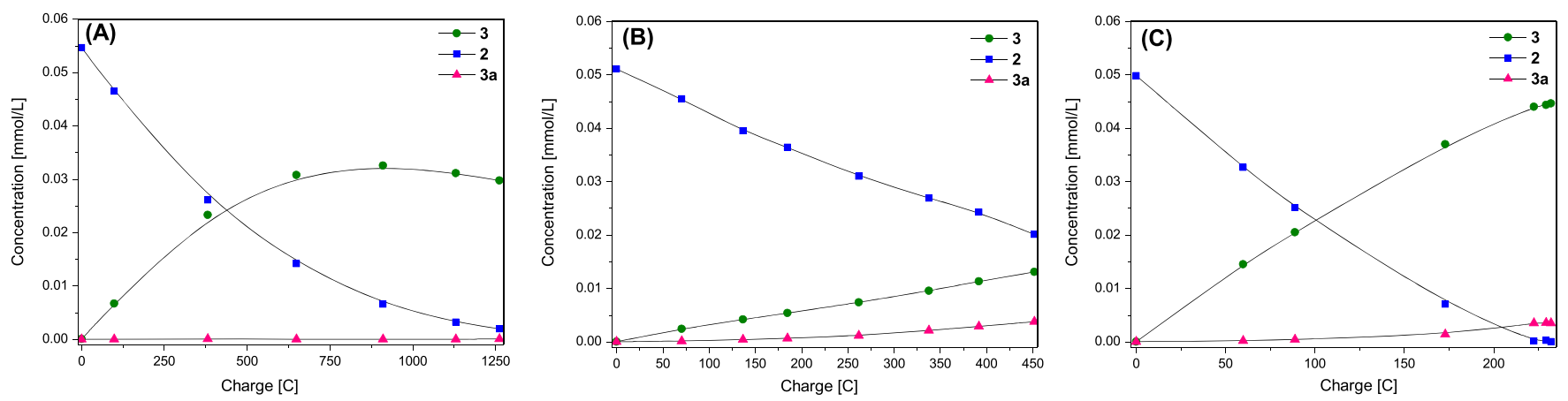

Figure 2. Oxidation of $0.05 \mathrm{M} 2$ to 3 and 3a in an electrochemical cell divided by Nafion 117 at (A) $12.6 \mathrm{~cm}^{2} \beta-\mathrm{PbO}_{2}$ at $1.8 \mathrm{~V}$ vs AglAgCl in $0.5 \mathrm{M}$ $\mathrm{H}_{2} \mathrm{SO}_{4}$; (B) $11.0 \mathrm{~cm}^{2} \mathrm{NiOOH}$ at $0.9 \mathrm{~V}$ vs AglAgCl in $0.34 \mathrm{M} \mathrm{Na}_{2} \mathrm{CO}_{3}+0.06 \mathrm{M} \mathrm{NaHCO}_{3}$; and (C) $4 \mathrm{~cm}^{2} 45$ ppi $\mathrm{RVC}$ at $0.8 \mathrm{~V}$ vs AglAgCl with $0.01 \mathrm{M}$ ACT in $0.34 \mathrm{M} \mathrm{Na}_{2} \mathrm{CO}_{3}+0.06 \mathrm{M} \mathrm{NaHCO}_{3}$.

sulfuric acid solutions has already been known for almost 100 years $^{26}$ and proceeds through the intermediate $2 a^{37,38}$ Starting around 1970, Zverev, Mil'man, and co-workers published a series of works describing the electrochemical production of $2 \mathrm{a}$ and 3 starting from 1 using $\mathrm{PbO}_{2}$ and carbon anodes, including the use of various mediators. ${ }^{39-42}$ As a result, 2a could be produced in near to quantitative yields (90-95\%) with high current efficiency $(\mathrm{CE})$ at $1.3 \mathrm{~V}$ vs saturated calomel electrode (SCE). Increasing the potential further to $>1.5 \mathrm{~V}$ vs SCE results in subsequent oxidation to 3 . However, this oxidation step appears to be less efficient, as furfural oxidation to 3 is faced by a low CE toward $3(30 \%)$ and moderate yield $(65 \%) .{ }^{34}$ These moderate yields and low CE for 3 prompted us to investigate the viability of an electrocatalytic strategy for the production of 3 via 2 as an intermediate.

The oxidation of aldehydes to carboxylic acids using stable nitroxyl radicals or nickel oxide hydroxide $(\mathrm{NiOOH})$ is well known. For example, the oxidation of HMF to 2,5furandicarboxylic acid (FDCA) was demonstrated using 2,2,6,6-tetramethylpiperidine-1-oxyl (TEMPO)-mediated electrochemical $^{54}$ or enzymatic ${ }^{6}$ oxidation and via electrocatalytic oxidation using NiOOH. ${ }^{55}$ The electrochemical systems typically use alkaline conditions; therefore, we evaluated the stability of 2 at various $\mathrm{pH}$ values. The investigation revealed that 2 is stable in sulfuric acid solutions $(\mathrm{pH} 0-1)$ but starts to degrade under alkaline conditions, with an increasing degradation rate at increasing $\mathrm{pH}$ (see Figure 1). This observation is in line with the literature reports where 2 a readily polymerizes to a water-soluble resinous material, ${ }^{56}$ and under alkaline conditions it isomerizes to the trans isomer, together with formation of a considerable amount of polymeric material. ${ }^{57}$ In contrast to that of sulfuric acid, the electrocatalytic activity of TEMPO, 4-acetamido-TEMPO (ACT), and $\mathrm{NiOOH}$ increases at increasing $\mathrm{pH}^{58,59}$ Due to the reduced stability of $\mathbf{2}$ under strongly alkaline conditions, electrochemical oxidation was investigated at $\mathrm{pH} 10$ using two different oxidative systems. The first one is ACT, which is lowcost, readily accessible, and outperforms other nitroxyls electrocatalytically, ${ }^{59}$ and the second one is $\mathrm{NiOOH}$, which circumvents downstream processing complexity compared to homogeneous catalysts. ${ }^{55}$

For comparison, electrochemical oxidation of 2 using $\beta$ $\mathrm{PbO}_{2}$ in $0.5 \mathrm{M} \mathrm{H}_{2} \mathrm{SO}_{4}$ was performed under conditions similar to those described for $1 .^{36}$ Initially a good selectivity was 
Scheme 3. Mechanism for the Oxidation of Substrate by the Laccase-TEMPO System (Left) ${ }^{63}$ and Electrocatalytic ACT System (Right) ${ }^{64}$

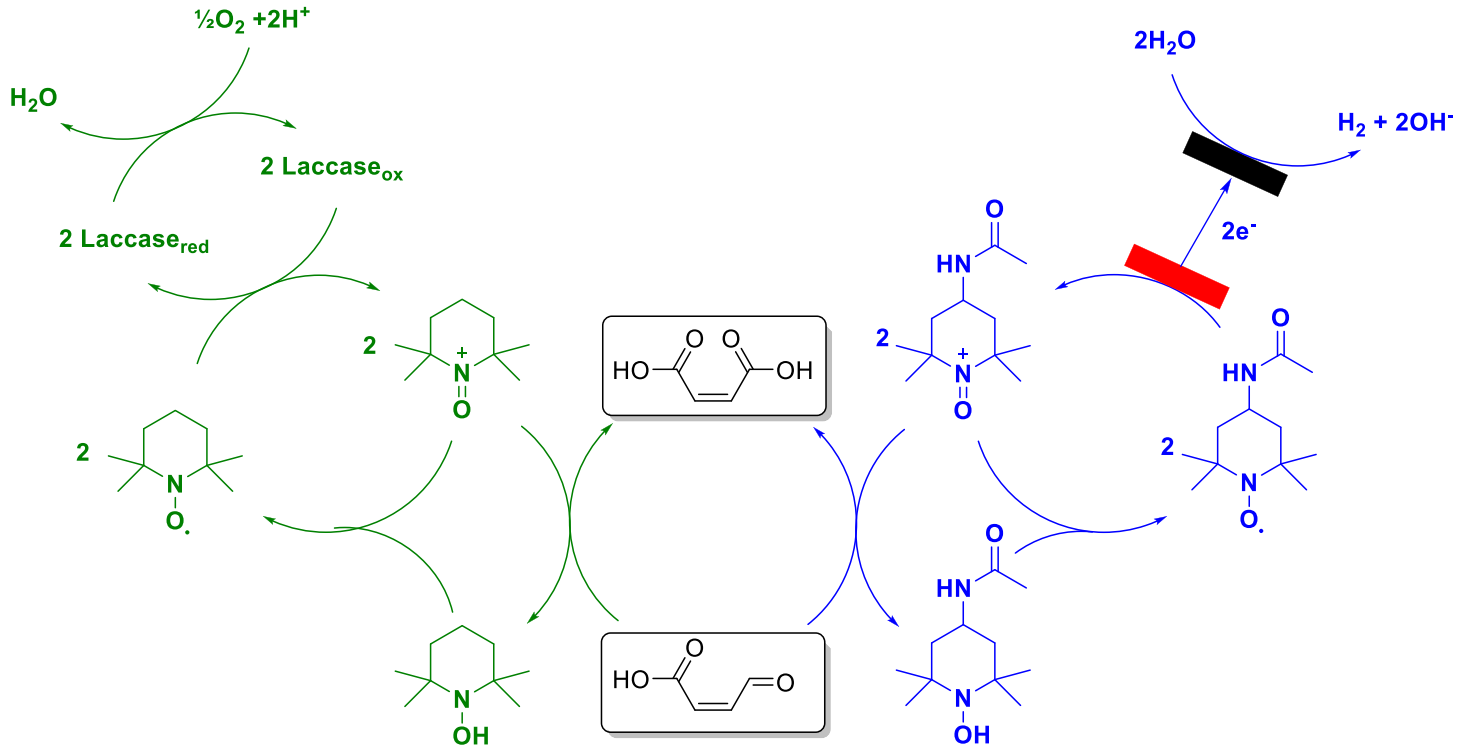

obtained, as illustrated in Figure 2a; however, at increasing conversion of $\mathbf{2}$, the selectivity toward the product 3 decreases, resulting in a maximum yield of $60 \%$ at $911 \mathrm{C}$ charge, $88 \%$ conversion of 2 , and $17 \% \mathrm{CE}$. These values are in line with the previous work of Kubota et $\mathrm{al}^{36}$ considering the nearquantitative conversion of $\mathbf{1}$ to 2 . At $\beta-\mathrm{PbO}_{2}$, hydroxyl radicals are formed which degrade 3 ultimately to carbon dioxide. ${ }^{60,61}$ At increasing electrochemical conversion of 2 , the concentration of 3 increases, thereby increasing the risk of degradation of 3 via hydroxyl radicals formed at $\beta-\mathrm{PbO}_{2}$. The maximum yield of 3 is then probably limited by the decreasing conversion rates of $\mathbf{2}$ to $\mathbf{3}$ and increasing degradation rate of 3 to ultimately $\mathrm{CO}_{2}$.

Oxidation of alcohols and aldehydes to the corresponding carboxylic acids can also be achieved using $\mathrm{NiOOH}$ under formation of $\mathrm{Ni}(\mathrm{OH})_{2}$, which is continuously electroregenerated to $\mathrm{NiOOH} .{ }^{55,62}$ The oxidation of $\mathbf{2}$ using $\mathrm{NiOOH}$ shows a similar trend to that with $\beta-\mathrm{PbO}_{2}$ with respect to its conversion vs supplied charge (Figure $2 \mathrm{~b}$ ). In contrast to the reaction with $\beta-\mathrm{PbO}_{2}$, the selectivity toward 3 remained constant at $42 \%$ during electrolysis, resulting in $26 \%$ yield at $61 \%$ conversion of 2 at $452 \mathrm{C}$ charge. Next to preferred 3 , its isomer fumaric acid (3a) was also formed in $7.4 \%$ yield. The appearance of additional peaks in the HPLC analyses indicates the formation of byproducts during the electrooxidation of $\mathbf{2}$ at $\mathrm{NiOOH}$, thus resulting in a low selectivity. One of the additional peaks has been identified as the trans isomer of 2a (see Supporting Information); analogous to the oxidation of $2 \mathrm{a}$ to 3 , the trans isomer oxidizes to $3 \mathbf{a}$. The vicinity of a double bond, e.g. $\alpha, \beta$-position, can result in cleavage at the double bond at $\mathrm{NiOOH} ;{ }^{62}$ however, no oxalic acid or acetic acid was detected in the HPLC analyses.

TEMPO or ACT is first activated by its enzymatic or electrochemical oxidation to the oxoammonium ion. This species then reacts with the substrate, leading to the formation of product and the hydroxylamine TEMPO derivative. Comproportionation of the hydroxylamine TEMPO derivative with the oxoammonium ion then regenerates the TEMPO/ ACT free radical. This free radical can then be reactivated for further rounds of catalysis. ${ }^{63-65}$

The formation of undesired products can be circumvented by using ACT instead of $\mathrm{NiOOH}$. ACT is oxidized at the reticulated vitreous carbon anode under formation of the corresponding oxoammonium ion $\left(\mathrm{ACT}^{+}\right)$, which subsequently oxidizes $\mathbf{2}$ to $\mathbf{3}$ under formation of the hydroxylamine form of ACT (ACTOH). ACT is then regenerated by comproportionation of $\mathrm{ACTOH}$ and $\mathrm{ACT}^{+} .64$ This catalytic process is illustrated in Scheme 3. Using ACT, the total yield of products ( 3 and $3 a$ ) is enhanced up to $97 \%$, including $7.1 \%$ of $3 a$, as indicated in Figure 2c. Moreover, the combined CE of $90 \%$ achieved for ACT is significantly higher compared to those of $\mathrm{NiOOH}(18 \%)$ and $\beta-\mathrm{PbO}_{2}(17 \%)$. Similar to the $\mathrm{NiOOH}$ system, the formation of $3 \mathrm{a}$ and the presence of the trans isomer of $\mathbf{2 a}$ were observed while using ACT. In both cases there is a progressive increase in the 3a concentration, probably due to increasing concentration of 3 .

However, after reaching complete conversion (>99\%) of 2 , electrolysis was continued further for approximately $40 \mathrm{~min}$, at negligible conversion, during which the amount of $3 a$ remained constant. The formation of $\mathbf{3 a}$ is attributed to the basecatalyzed (slow) isomerization of $2 \mathbf{a}$ to the trans isomer, ${ }^{57}$ followed by subsequent oxidation to $\mathbf{3 a}$ under applied conditions.

The performance of ACT for the electrocatalytic oxidation of 2 to 3 is superior to that of $\mathrm{NiOOH}$ and $\beta-\mathrm{PbO}_{2}$ in terms of the obtained selectivity, current efficiency, and applied electrode potential. In addition, to the best of our knowledge, this is the first report describing the nitroxyl-mediated oxidation of an $\alpha, \beta$-unsaturated aldehyde to the corresponding acid.

Step 2: (b) Enzymatic Oxidation of 2 to Maleic Acid 3. Inspired by the electrochemical activation of nitroxyl radicals for the efficient oxidation of $\mathbf{2}$, we were prompted to investigate its enzymatic oxidation in a similar fashion, i.e., 
conversion of aldehydes to carboxylic acids under mild reaction conditions using the laccase-TEMPO system.

The laccase-TEMPO system involves the action of the copper-dependent oxidative enzyme laccase and the mediator TEMPO, which enables the oxidation of substrates that are not directly oxidized by the enzyme. The mechanism of substrate oxidation by this system is shown in Scheme 3. TEMPO is first oxidized to its oxoammonium ion $\left(\mathrm{TEMPO}^{+}\right)$by laccase.

Subsequently, TEMPO ${ }^{+}$oxidizes the substrate to give the desired product and a hydroxylamine TEMPO derivative (TEMPOH). TEMPO is then regenerated by comproportionation of TEMPOH with TEMPO ${ }^{+}$. The reduced laccase is reoxidized by molecular oxygen, enabling it to oxidize the TEMPO free radical, starting a new catalytic cycle. ${ }^{63,66}$ The laccase-TEMPO system has previously been employed for the oxidations of alcohols to aldehydes, aldehydes to carboxylic acids, and amines to imines. ${ }^{6,67}$ To develop our two-step reaction sequence for the conversion of 1 to 3 further, we investigated the potential of this mild oxidation method for the conversion of the intermediate 2 to 3 .

To this end, we have investigated the oxidation of 2 using the laccase-TEMPO system at different concentrations of laccase from Trametes versicolor and TEMPO. The results are shown in Table 1. At the highest laccase and TEMPO

Table 1. Conversion of $50 \mathrm{mM} 2$ to 3 by the LaccaseTEMPO System in $100 \mathrm{mM}$ Sodium Acetate Buffer $\mathrm{pH} 4.5$ and $15 \%$ Acetone at $25{ }^{\circ} \mathrm{C}$

\begin{tabular}{|c|c|c|c|c|c|c|}
\hline \multirow[b]{3}{*}{ entry } & \multirow[b]{3}{*}{$\begin{array}{c}\text { TEMPO } \\
(\mathrm{mM})\end{array}$} & \multirow[b]{3}{*}{$\begin{array}{l}\text { laccase } \\
(\mathrm{mg} / \mathrm{mL})\end{array}$} & \multicolumn{4}{|c|}{ time duration } \\
\hline & & & \multicolumn{2}{|c|}{$6 \mathrm{~h}$} & \multicolumn{2}{|c|}{$24 \mathrm{~h}$} \\
\hline & & & $\begin{array}{c}2 \text { conv } \\
(\%)\end{array}$ & $\begin{array}{c}3 \text { yield } \\
(\%)\end{array}$ & $\begin{array}{c}2 \text { conv } \\
(\%)\end{array}$ & $\begin{array}{c}3 \text { yield } \\
(\%)\end{array}$ \\
\hline 1 & 50 & 2 & 75 & 75 & $>99$ & $>99$ \\
\hline 2 & 50 & 0.2 & $17^{a}$ & $21^{a}$ & 64 & 61 \\
\hline 3 & 10 & 2 & 26 & 19 & 23 & 22 \\
\hline 4 & 10 & 0.2 & 6 & 6 & 22 & 16 \\
\hline 5 & 50 & - & $<5$ & $<5$ & $<5$ & $<5$ \\
\hline 6 & - & 2 & - & - & - & - \\
\hline
\end{tabular}

${ }^{a}$ The conversion of 2 being lower than the yield of 3 at $6 \mathrm{~h}$ is attributed to experimental error in the determination of the concentration of $\mathbf{2}$. The observed difference is explained by an error of $<5 \%$ in this value.

concentrations tested, $75 \%$ conversion of 2 to 3 was observed after $6 \mathrm{~h}$, and by prolonging the reaction to $24 \mathrm{~h}$, quantitative conversion to the desired product with $100 \%$ selectivity was observed (Table 1, entry 1). At lower concentrations of either TEMPO or laccase, lower conversions to 3 were observed (Table 1, entries 2-4). In all reactions, the conversion of 2 to 3 was highly selective, with no byproducts being formed in quantifiable amounts. Control reactions from which either TEMPO or laccase was omitted were also performed. When 2 was incubated with TEMPO in the absence of laccase, trace amounts of 3 were formed (Table 1, entry 5). This is likely due to the direct oxidation of TEMPO by molecular oxygen, followed by its reaction with 2 to give 3 . On the other hand, no conversion was observed even after $24 \mathrm{~h}$ when 2 was reacted only with enzyme (laccase) in the absence of TEMPO. These observations clearly show that either laccase or TEMPO alone is not capable of efficiently oxidizing 2 (Table 1, entries 5 and 6).
Thus, the laccase-TEMPO system facilitates the oxidation strategy very efficiently by converting 2 to 3 in a quantitative yield with high selectivity. In addition, the reaction is performed under mild conditions (room temperature), which is attractive from the point of view of energy efficiency.

\section{CONCLUSIONS}

We have successfully demonstrated the use of greener technologies based on photo-, electro-, and biochemistry for the efficient synthesis of maleic acid from furfural. Furthermore, the work also reports two different promising strategies for the production of $\mathbf{3}$ starting from precursor 2 . The stable nitroxyl radicals TEMPO and ACT can be easily activated using both electrochemical and enzymatic methods favoring the efficient oxidation of $\mathbf{2}$ to $\mathbf{3}$ with excellent selectivity.

The electrocatalytic oxidation of $\mathbf{2}$, utilizing ACT as catalyst, exhibited superior performance over other electrochemical systems in terms of conversion, current efficiency, selectivity, and overall $97 \%$ yield to 3 (including $7.1 \%$ of the other isomer, fumaric acid 3a). Similarly, the laccase-TEMPO-catalyzed enzymatic oxidation is also highly effective in converting 2 to 3 in high selectivity with no formation of quantifiable amounts of byproducts. Further development will enable the enzyme and TEMPO loadings to be optimized to make this process feasible for large-scale industrial production. To the best of our knowledge, this is the first report describing the oxidation of 1 to 3 via the intermediate 2 using stable nitroxyl radicals.

To conclude, the technology integration of photocatalytic conversion of furfural to $\mathbf{2}$, followed by oxidation via either an electrochemical or enzymatic approach, to produce maleic acid is an attractive, greener strategy and will certainly enable the large-scale production of bulk chemicals such as maleic acid at lower cost from biomass compared to current fossil-based feedstocks and production.

\section{ASSOCIATED CONTENT}

\section{Supporting Information}

The Supporting Information is available free of charge at https://pubs.acs.org/doi/10.1021/acssuschemeng.0c02833.

Materials and methods; details of synthesis, stability, and degradation experiments of 5-hydroxy-2-(5H)-furanone 2 ; investigation on the identification of trans- $\beta$ formylacrylic acid; general procedure for the electrochemical and enzymatic oxidation reactions (PDF)

\section{AUTHOR INFORMATION}

\section{Corresponding Author}

Shanmugam Thiyagarajan - Wageningen Food \& Biobased Research, 6708 WG Wageningen, The Netherlands; (1) orcid.org/0000-0002-7905-4233;

Email: shanmugam.thiyagarajan@wur.nl

\section{Authors}

David Franciolus - Wageningen Food \& Biobased Research, 6708 WG Wageningen, The Netherlands

Roel J. M. Bisselink - Wageningen Food \& Biobased Research, 6708 WG Wageningen, The Netherlands

Tom A. Ewing - Wageningen Food \& Biobased Research, 6708 WG Wageningen, The Netherlands; 이이.org/0000-00026944-887X 
Carmen G. Boeriu - Wageningen Food \& Biobased Research, 6708 WG Wageningen, The Netherlands; 10 orcid.org/00000003-4903-6621

Jacco van Haveren - Wageningen Food \& Biobased Research, 6708 WG Wageningen, The Netherlands

Complete contact information is available at:

https://pubs.acs.org/10.1021/acssuschemeng.0c02833

\section{Notes}

The authors declare no competing financial interest.

\section{ACKNOWLEDGMENTS}

The work has been performed within the SCELIO-4B project, a project funded by the Research Programme OP-Zuid; an EU Programme for regional development.

\section{REFERENCES}

(1) Bozell, J. J. Feedstocks for the Future: Using Technology Development as a Guide to Product Identification. In Feedstocks for the Future: Renewables for the Production of Chemicals and Materials; Bozell, J. J., Patel, M. K., Eds.; ACS Symposium Series 921; American Chemical Society, 2006; Chap. 1, pp 1-12..

(2) Metzger, J. O.; Biermann, U. Sustainable Development and Renewable Feedstocks for Chemical Industry. In Feedstocks for the Future: Renewables for the Production of Chemicals and Materials; Bozell, J. J., Patel, M. K., Eds.; ACS Symposium Series 921; American Chemical Society, 2006; Chap. 2, pp 13-26. .

(3) Manzer, L. E. Biomass Derivatives: A Sustainable Source of Chemicals. In Feedstocks for the Future: Renewables for the Production of Chemicals and Materials; Bozell, J. J., Patel, M. K., Eds.; ACS Symposium Series 921; American Chemical Society, 2006; Chap. 4, pp $40-51$..

(4) Gallezot, P.; Besson, M.; Djakovitch, L.; Perrard, A.; Pinel, C.; Sorokin, A. Catalytic Transformations of Carbohydrates. In Feedstocks for the Future: Renewables for the Production of Chemicals and Materials; Bozell, J. J., Patel, M. K., Eds.; ACS Symposium Series 921; American Chemical Society, 2006; Chap. 5, pp 52-66..

(5) Kiran, D.; Patil, D. K. Review of Green Chemical Technologies for Sustainable Developments in Chemical Process Industries. Trends Chem. Eng. 2014, 2, 12-19.

(6) Wang, K.-F.; Liu, C.-1.; Sui, K.-y.; Guo, C.; Liu, C.-Z. Efficient Catalytic Oxidation of 5-Hydroxymethylfurfural to 2,5-Furandicarboxylic Acid by Magnetic Laccase Catalyst. ChemBioChem 2018, 19 (7), 654-659.

(7) Wojcieszak, R.; Santarelli, F.; Paul, S.; Dumeignil, F.; Cavani, F.; Gonçalves, R. V. Recent developments in maleic acid synthesis from bio-based chemicals. Sustainable Chem. Processes 2015, 3 (1), 1-11.

(8) Centi, G.; Trifiro, F.; Ebner, J. R.; Franchetti, V. M. Mechanistic aspects of maleic anhydride synthesis from $\mathrm{C} 4$ hydrocarbons over phosphorus vanadium oxide. Chem. Rev. 1988, 88 (1), 55-80.

(9) Benvenuto, M. A. Polymers. Industrial Organic Chemistry; De Gruyter, 2017; Chap. 12, pp 81-91, .

(10) Yang, M.; Liu, B.-t.; Gao, G.; Liu, X.-1.; Liu, F.-q. Poly(maleic anhydride-co-acrylic acid)/poly(ethylene glycol) hydrogels with $\mathrm{pH}$ and ionic-strength-responses. Chin. J. Polym. Sci. 2010, 28 (6), 951959.

(11) Plastic Packaging: Interactions with Food and Pharmaceuticals, 2nd ed.; Piringer, O. G., Baner, A. L., Eds.; Wiley, 2008; pp I-XVIII..

(12) Maleic Anhydride, Maleic Acid, and Fumaric Acid. In Van Nostrand's Scientific Encyclopedia; Considine, G. D., Ed.; Wiley, 2006. DOI: $10.1002 / 0471743984$.vse8095.

(13) Hood, D. K.; Musa, O. M. Application of Maleic AnhydrideBased Materials. In Handbook of Maleic Anhydride Based Materials: Syntheses, Properties and Applications; Musa, O. M., Ed.; Springer International Publishing: Cham, Switzerland, 2016; Chap. 10, pp 509-575..
(14) Thiyagarajan, S.; Genuino, H. C.; Śliwa, M.; van der Waal, J. C.; de Jong, E.; van Haveren, J.; Weckhuysen, B. M.; Bruijnincx, P. C. A.; van Es, D. S. Substituted Phthalic Anhydrides from Biobased Furanics: A New Approach to Renewable Aromatics. ChemSusChem 2015, 8 (18), 3052-3056.

(15) Thiyagarajan, S.; Genuino, H. C.; van der Waal, J. C.; de Jong, E.; Weckhuysen, B. M.; van Haveren, J.; Bruijnincx, P. C. A.; van Es, D. S. A Facile Solid-Phase Route to Renewable Aromatic Chemicals from Biobased Furanics. Angew. Chem., Int. Ed. 2016, 55 (4), 13681371.

(16) Alba-Rubio, A. C.; Fierro, J. L. G.; Leon-Reina, L.; Mariscal, R.; Dumesic, J. A.; Lopez Granados, M. Oxidation of furfural in aqueous $\mathrm{H} 2 \mathrm{O} 2$ catalysed by titanium silicalite: Deactivation processes and role of extraframework Ti oxides. Appl. Catal., B 2017, 202, 269-280.

(17) Gandarias, I.; García-Fernández, S.; Obregón, I.; AgirrezabalTelleria, I.; Arias, P. L. Production of 2-methylfuran from biomass through an integrated biorefinery approach. Fuel Process. Technol. 2018, 178, 336-343.

(18) Marcotullio, G. The Chemistry and Technology of Furfural Production in Modern Lignocellulose-Feedstock Biorefineries. Ph.D. Thesis, Delft University of Technology, 2011.

(19) Furfuryl alcohol. In The Chemistry and Technology of Furfural and Its Many By-productsSugar SeriesVol. 13; Zeitsch, K. J., Ed.; Elsevier, 2000; Chap. 17, pp 150-155. DOI: 10.1016/S01677675(00)80017-2.

(20) Gallo, J. M. R.; Alonso, D. M.; Mellmer, M. A.; Yeap, J. H.; Wong, H. C.; Dumesic, J. A. Production of Furfural from Lignocellulosic Biomass Using Beta Zeolite and Biomass-Derived Solvent. Top. Catal. 2013, 56 (18), 1775-1781.

(21) Karinen, R.; Vilonen, K.; Niemelä, M. Biorefining: Heterogeneously Catalyzed Reactions of Carbohydrates for the Production of Furfural and Hydroxymethylfurfural. ChemSusChem 2011, 4 (8), $1002-1016$

(22) Rodenas, Y.; Mariscal, R.; Fierro, J. L. G.; Martín Alonso, D.; Dumesic, J. A.; López Granados, M. Improving the production of maleic acid from biomass: TS-1 catalysed aqueous phase oxidation of furfural in the presence of $\gamma$-valerolactone. Green Chem. 2018, 20 (12), 2845-2856.

(23) Lohbeck, K.; Haferkorn, H.; Fuhrmann, W.; Fedtke, N.Maleic and Fumaric Acids. Ullmann's Encyclopedia of Industrial Chemistry; Wiley, 2000. DOI: 10.1002/14356007.a16 053.

(24) Bissot, T. C.; Benson, K. A. Oxidation of Butane to Maleic Anhydride. Ind. Eng. Chem. Prod. Res. Dev. 1963, 2 (1), 57-60.

(25) Luo, Y.; Li, Z.; Li, X.; Liu, X.; Fan, J.; Clark, J. H.; Hu, C. The production of furfural directly from hemicellulose in lignocellulosic biomass: A review. Catal. Today 2019, 319, 14-24.

(26) Teijiro, Y. Process of preparing Maleic acid and Succinic acid from Furfural by Electrolysis. U.S. Patent US1709297A, 1926.

(27) Sessions, W. V. Catalytic Oxidation of Furfural in the Vaopur Phase. J. Am. Chem. Soc. 1928, 50 (6), 1696-1698.

(28) Li, X.; Ko, J.; Zhang, Y. Highly Efficient Gas-Phase Oxidation of Renewable Furfural to Maleic Anhydride over Plate Vanadium Phosphorus Oxide Catalyst. ChemSusChem 2018, 11 (3), 612-618.

(29) Murthy, M. S.; Rajamani, K. Kinetics of vapour phase oxidation of furfural on vanadium catalyst. Chem. Eng. Sci. 1974, 29 (2), 601609

(30) Lan, J.; Chen, Z.; Lin, J.; Yin, G. Catalytic aerobic oxidation of renewable furfural to maleic anhydride and furanone derivatives with their mechanistic studies. Green Chem. 2014, 16 (9), 4351-4358.

(31) Guo, H.; Yin, G. Catalytic Aerobic Oxidation of Renewable Furfural with Phosphomolybdic Acid Catalyst: an Alternative Route to Maleic Acid. J. Phys. Chem. C 2011, 115 (35), 17516-17522.

(32) Shi, S.; Guo, H.; Yin, G. Synthesis of maleic acid from renewable resources: Catalytic oxidation of furfural in liquid media with dioxygen. Catal. Commun. 2011, 12 (8), 731-733.

(33) Li, X.; Ho, B.; Lim, D. S. W.; Zhang, Y. Highly efficient formic acid-mediated oxidation of renewable furfural to maleic acid with $\mathrm{H}_{2} \mathrm{O}_{2}$. Green Chem. 2017, 19 (4), 914-918. 
(34) Araji, N.; Madjinza, D. D.; Chatel, G.; Moores, A.; Jérôme, F.; De Oliveira Vigier, K. Synthesis of maleic and fumaric acids from furfural in the presence of betaine hydrochloride and hydrogen peroxide. Green Chem. 2017, 19 (1), 98-101.

(35) Li, X.; Lan, X.; Wang, T. Selective oxidation of furfural in a biphasic system with homogeneous acid catalyst. Catal. Today 2016 276, 97-104.

(36) Kubota, S. R.; Choi, K.-S. Electrochemical Valorization of Furfural to Maleic Acid. ACS Sustainable Chem. Eng. 2018, 6 (8), 9596-9600.

(37) Hellström, A. N. Om elektrolytisk oxidation av furfurol. Svensk Kemisk Tidskrift 1948, 60, 214-220.

(38) Zverev, V. A.; Koshutin, V. I.; Ezhechenko, V. B. Electrochemical oxidation of furan, cyclopentadiene and their derivatives. Elektrokhimiya 1977, 13, 1832-1834.

(39) Smirnov, V. A.; Milman, V. I.; Krayanskii, O. B. Electrochemical oxidation of furfural. Elektrokhimiya 1971, 7, 830-834.

(40) Milman, V. I.; Zverev, V. A.; Smirnov, V. A.; Klebanov, Y. S. Effect of homogeneous catalysts on electrochemical synthesis of 3formylacrylic acid. Elektrokhimiya 1978, 14, 1555-1558.

(41) Milman, V. I.; Sycheva, G. M. Oxidation of furfural on a carbon electrode. Elektrokhimiya 1985, 21, 1206-1208.

(42) Milman, V. I.; Sycheva, G. M. Determination of the parameters of electrochemical furfural oxidation at a carbon electrode in a continuous cell. Elektrokhimiya 1986, 22, 1647-1648.

(43) Wu, H.; Song, J.; Liu, H.; Xie, Z.; Xie, C.; Hu, Y.; Huang, X.; Hua, M.; Han, B. An electrocatalytic route for transformation of biomass-derived furfural into 5-hydroxy-2(5H)-furanone. Chemical Science 2019, 10, 4692-4698.

(44) Román, A. M.; Hasse, J. C.; Medlin, J. W.; Holewinski, A. Elucidating Acidic Electro-Oxidation Pathways of Furfural on Platinum. ACS Catal. 2019, 9 (11), 10305-10316.

(45) Alonso-Fagundez, N.; Agirrezabal-Telleria, I.; Arias, P. L.; Fierro, J. L. G.; Mariscal, R.; Granados, M. L. Aqueous-phase catalytic oxidation of furfural with $\mathrm{H} 2 \mathrm{O} 2$ : high yield of maleic acid by using titanium silicalite-1. RSC Adv. 2014, 4 (98), 54960-54972.

(46) Chen, B.; Li, F.; Yuan, G. Selective hydrodeoxygenation of 5hydroxy-2 $(5 \mathrm{H})$-furanone to $\gamma$-butyrolactone over $\mathrm{Pt} /$ mesoporous solid acid bifunctional catalyst. RSC Adv. 2017, 7 (34), 21145-21152.

(47) de Jong, J. C.; van Bolhuis, F.; Feringa, B. L. Asymmetric DielsAlder reactions with 5-menthyloxy-2-(5H)-furanone. Tetrahedron: Asymmetry 1991, 2 (12), 1247-1262.

(48) Carney, J. M.; Hammer, R. J.; Hulce, M.; Lomas, C. M.; Miyashiro, D. Microphotochemistry Using 5-mm Light-Emitting Diodes: Energy-Efficient Photooxidations. Synthesis 2012, 44 (16), $2560-2566$

(49) Esser, P.; Pohlmann, B.; Scharf, H.-D. The Photochemical Synthesis of Fine Chemicals with Sunlight. Angew. Chem., Int. Ed. Engl. 1994, 33 (20), 2009-2023.

(50) Valverde, D.; Porcar, R.; Izquierdo, D.; Burguete, M. I.; GarciaVerdugo, E.; Luis, S. V. Rose Bengal Immobilized on Supported IonicLiquid-like Phases: An Efficient Photocatalyst for Batch and Flow Processes. ChemSusChem 2019, 12, 3996-4004.

(51) Rodrìguez, S.; Vidal, A.; Monroig, J. J.; González, F. V. Diastereoselectivity in the epoxidation of $\gamma$-hydroxy $\alpha, \beta$-unsaturated esters: temperature and solvent effect. Tetrahedron Lett. 2004, 45 (28), 5359-5361.

(52) Astarita, A.; Cermola, F.; DellaGreca, M.; Iesce, M. R.; Previtera, L.; Rubino, M. Photooxygenation of furans in water and ionic liquid solutions. Green Chem. 2009, 11 (12), 2030-2033.

(53) Salles, A. G.; Zarra, S.; Turner, R. M.; Nitschke, J. R. A SelfOrganizing Chemical Assembly Line. J. Am. Chem. Soc. 2013, 135 (51), 19143-19146.

(54) Cha, H. G.; Choi, K.-S. Combined biomass valorization and hydrogen production in a photoelectrochemical cell. Nat. Chem. 2015, $7,328-333$.

(55) Latsuzbaia, R.; Bisselink, R.; Anastasopol, A.; van der Meer, H.; van Heck, R.; Yagüe, M. S.; Zijlstra, M.; Roelands, M.; Crockatt, M.; Goetheer, E.; Giling, E. Continuous electrochemical oxidation of biomass derived 5-(hydroxymethyl)furfural into 2,5-furandicarboxylic acid. J. Appl. Electrochem. 2018, 48 (6), 611-626.

(56) Dunlop, A. P.; Stout, P. R.; Swadesh, S. Autoxidation of Furfural. Ind. Eng. Chem. 1946, 38 (7), 705-708.

(57) Grove, M. D.; Weisleder, D. Hydrolysis products of 4acetamido-4-hydroxy-2-butenoic acid gamma.-lactone. J. Org. Chem. 1973, 38 (4), 815-816.

(58) Robertson, P. M. On the oxidation of alcohols and amines at nickel oxide electrodes: Mechanistic aspects. J. Electroanal. Chem. Interfacial Electrochem. 1980, 111 (1), 97-104.

(59) Rafiee, M.; Miles, K. C.; Stahl, S. S. Electrocatalytic Alcohol Oxidation with TEMPO and Bicyclic Nitroxyl Derivatives: Driving Force Trumps Steric Effects. J. Am. Chem. Soc. 2015, 137 (46), $14751-14757$.

(60) Cong, Y.; Wu, Z. Electrocatalytic Generation of Radical Intermediates over Lead Dioxide Electrode Doped with Fluoride. J. Phys. Chem. C 2007, 111 (8), 3442-3446.

(61) Yokoyama, M.; Ishikawa, W. Die Electrochemische Oxydation Des Tolu p-Chinons. Bull. Chem. Soc. Jpn. 1931, 6 (10), 275-284.

(62) Kaulen, J.; Schäfer, H.-J. Oxidation of alcohols by electrochemically regenerated nickel oxide hydroxide. Selective oxidation of hydroxysteroids. Tetrahedron 1982, 38 (22), 3299-3308.

(63) Tromp, S. A.; Matijošyte, I.; Sheldon, R. A.; Arends, I. W. C. E.; Mul, G.; Kreutzer, M. T.; Moulijn, J. A.; De Vries, S. Mechanism of Laccase-TEMPO-Catalyzed Oxidation of Benzyl Alcohol. ChemCatChem 2010, 2 (7), 827-833.

(64) Carlsson, D. O.; Lindh, J.; Nyholm, L.; Strømme, M.; Mihranyan, A. Cooxidant-free TEMPO-mediated oxidation of highly crystalline nanocellulose in water. RSC Adv. 2014, 4 (94), 5228952298.

(65) Nutting, J. E.; Rafiee, M.; Stahl, S. S. Tetramethylpiperidine NOxyl (TEMPO), Phthalimide N-Oxyl (PINO), and Related N-Oxyl Species: Electrochemical Properties and Their Use in Electrocatalytic Reactions. Chem. Rev. 2018, 118 (9), 4834-4885.

(66) Mogharabi, M.; Faramarzi, M. A. Laccase and laccase-mediated systems in the synthesis of organic compounds. Adv. Synth. Catal. 2014, 356 (5), 897-927.

(67) Galletti, P.; Pori, M.; Funiciello, F.; Soldati, R.; Ballardini, A.; Giacomini, D. Laccase-Mediator System for Alcohol Oxidation to Carbonyls or Carboxylic Acids: Toward a Sustainable Synthesis of Profens. ChemSusChem 2014, 7 (9), 2684-2689. 